\title{
Low forced vital capacity predicts poor prognosis in gastric cancer patients
}

\author{
Fan Feng ${ }^{1, *}$, Yangzi Tian ${ }^{2, *}$, Yuan Zang ${ }^{3, *}$, Li Sun ${ }^{1}$, Liu Hong ${ }^{1}$, Jianjun Yang ${ }^{1}$,

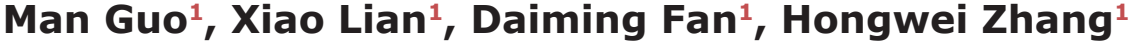 \\ ${ }^{1}$ Division of Digestive Surgery, Xijing Hospital of Digestive Disease, Fourth Military Medical University, 710032, Xi'an, \\ Shaanxi, China \\ ${ }^{2}$ Department of Dermatology, Xijing Hospital, Fourth Military Medical University, 710032, Xi'an, Shaanxi, China \\ ${ }^{3}$ Department of Orthopedics, Xijing Hospital, Fourth Military Medical University, 710032, Xi'an, Shaanxi, China \\ *These authors have contributed equally to this work \\ Correspondence to: Hongwei Zhang, email: zhanghwfmmu@126.com \\ Keywords: gastric cancer, forced vital capacity, maximal voluntary ventilation, postoperative complications, prognosis \\ Received: August 17, $2016 \quad$ Accepted: February 14, $2017 \quad$ Published: March 07, 2017 \\ Copyright: Feng et al. This is an open-access article distributed under the terms of the Creative Commons Attribution License (CC- \\ BY), which permits unrestricted use, distribution, and reproduction in any medium, provided the original author and source are \\ credited.
}

\section{ABSTRACT}

\begin{abstract}
Preoperative pulmonary function assessment is used to select surgical candidates and predict the occurrence of postoperative complications. The present study enrolled 1210 gastric cancer patients (949 males and 261 females). Forced vital capacity (FVC) and maximal voluntary ventilation (MVV) were measured as a percent of predicted values. We then analyzed associations between patient pulmonary function and both prognosis and postoperative complications. Patient 1-, 3- and 5-year overall survival rates were $\mathbf{8 8 . 8} \%, 65.7 \%$ and $\mathbf{5 3 . 0 \%}$, respectively. FVC and MVV optimal cutoff values were $87.0(P=0.003)$ and $83.6(P=0.026)$, respectively. Low FVC and low MVV were associated with higher rates of postoperative fever $(23.8 \%$ vs. $13.9 \%, P<0.001 ; 17.8 \%$ vs. $13.3 \%, P=0.049$, respectively) and poor patient prognosis (5-year overall survival: $43.5 \%$ vs. $57.6 \%, P=0.003 ; 51.8 \%$ vs. $54.3 \%, P=0.026$, respectively). Only low FVC was an independent prognostic predictor for gastric cancer $(P=0.012)$. In subgroup analyses, FVC was not associated with stage I or II gastric cancer patient prognoses $(P>0.05)$, but low FVC was an independent risk factor for poor prognosis in stage III gastric cancer cases $(P=0.004)$. These findings indicate that low FVC is predictive of poorer prognosis and higher risk of postoperative fever in gastric cancer patients.
\end{abstract}

\section{INTRODUCTION}

Gastric cancer is the fifth most common malignancy, and the third leading cause of cancer-related death worldwide [1], although incidences have declined in recent decades. Surgical therapy remains the optimal treatment for non-metastatic gastric cancer. Still, even with advances in surgical techniques and adjuvant therapy options, advanced gastric cancer patient prognoses are poor [2].

Surgeons commonly encounter patients with impaired pulmonary function during preoperative evaluation. Pulmonary comorbidity increases the risk of postoperative respiratory complications [3]. Thus, preoperative evaluation of pulmonary function is widely used to select surgical candidates and predict the occurrence of postoperative respiratory complications, especially in the field of thoracic surgery [4]. Recent studies also investigated the influence of pulmonary function on abdominal surgery outcomes $[5,6]$. However, the prognostic value of preoperative pulmonary function in gastric cancer patients has not yet been investigated. The present study assessed the value of pulmonary function in predicting gastric cancer patient prognosis and the likelihood of postoperative complications. 
Table 1: Clinicopathological characteristics of gastric cancer patients

\begin{tabular}{|c|c|c|}
\hline Characteristics & Number $(\mathrm{n}=1210)$ & Percent \\
\hline \multicolumn{3}{|l|}{ Gender } \\
\hline Male & 949 & 78.4 \\
\hline Female & 261 & 21.6 \\
\hline \multicolumn{3}{|l|}{ Age } \\
\hline$\leq 60$ & 701 & 38.0 \\
\hline$>60$ & 509 & 62.0 \\
\hline \multicolumn{3}{|l|}{ BMI } \\
\hline$<18.5$ & 107 & 8.9 \\
\hline$\geq 18.5-<25.0$ & 862 & 71.2 \\
\hline$\geq 25.0$ & 241 & 19.9 \\
\hline \multicolumn{3}{|l|}{ Total protein } \\
\hline$<65.0$ & 338 & 27.9 \\
\hline$\geq 65.0$ & 872 & 72.1 \\
\hline \multicolumn{3}{|l|}{ Albumin } \\
\hline$<40.0$ & 264 & 21.8 \\
\hline$\geq 40.0$ & 946 & 78.2 \\
\hline \multicolumn{3}{|l|}{ Tumor location } \\
\hline Upper third & 425 & 35.1 \\
\hline Middle third & 201 & 16.6 \\
\hline Lower third & 502 & 41.5 \\
\hline Entire & 82 & 6.8 \\
\hline \multicolumn{3}{|l|}{ Tumor size $(\mathrm{cm})$} \\
\hline$\leq 5$ & 810 & 66.9 \\
\hline$>5$ & 400 & 33.1 \\
\hline \multicolumn{3}{|l|}{ Borrmann type } \\
\hline I & 155 & 15.7 \\
\hline II & 320 & 32.3 \\
\hline III & 426 & 43.1 \\
\hline IV & 88 & 8.9 \\
\hline \multicolumn{3}{|l|}{ Pathological type } \\
\hline Well differentiated & 104 & 8.6 \\
\hline Moderately differentiated & 308 & 25.5 \\
\hline Poorly differentiated & 754 & 62.3 \\
\hline Signet ring cell or Mucinous & 44 & 3.6 \\
\hline \multicolumn{3}{|l|}{ Tumor depth } \\
\hline $\mathrm{T} 1$ & 223 & 18.4 \\
\hline $\mathrm{T} 2$ & 111 & 9.2 \\
\hline
\end{tabular}

(Continued) 


\begin{tabular}{lcc}
\hline Characteristics & Number $(\mathbf{n}=\mathbf{1 2 1 0})$ & Percent \\
\hline T3 & 433 & 35.8 \\
T4 & 443 & 36.6 \\
Lymph node metastasis & & \\
N0 & 413 & 34.1 \\
N1 & 210 & 17.4 \\
N2 & 206 & 17.0 \\
N3 & 381 & 31.5 \\
Tumor stage & & \\
I & 265 & 21.9 \\
II & 330 & 27.3 \\
III & 615 & 50.8 \\
\hline
\end{tabular}

\section{RESULTS}

Our study included 949 male (78.4\%) and 261 female $(21.6 \%)$ gastric cancer patients (Table 1$)$. Median patient age was 59 years (range: 20-87), and median follow-up time was 25 months (range: 1-75). Patient 1-, 3 - and 5-year overall survival rates were $88.8 \%, 65.7 \%$ and $53.0 \%$, respectively (Figure 1 ).

Forced vital capacity (FVC) and maximal voluntary ventilation (MVV) optimal cutoff values were $87.0(\mathrm{P}=0.003)$ and $83.6(\mathrm{P}=0.026)$, respectively. Baseline characteristics of patients with low versus high FVC and MVV levels were analyzed and shown in Supplementary Table 1. We found that FVC level was

associated with gender, age, body mass index (BMI), albumin, tumor size, and tumor stage $(\mathrm{P}<0.05)$. MVV level was associated with age, BMI, total protein, albumin, tumor size, lymph node metastasis, and tumor stage $(\mathrm{P}<0.05)$.

Our results showed that low FVC and low MVV were associated with poor prognosis in gastric cancer patients (Figure $2 \& 3$ ). A univariate analysis showed that patient age, BMI, total protein, albumin, tumor size, Borrmann type, pathological type, tumor depth, lymph node metastasis, tumor stage, FVC, and MVV were associated with prognosis (Table 2). However, only age, BMI, tumor depth, lymph node metastasis, and FVC were independent prognostic predictors (Table 3 ).

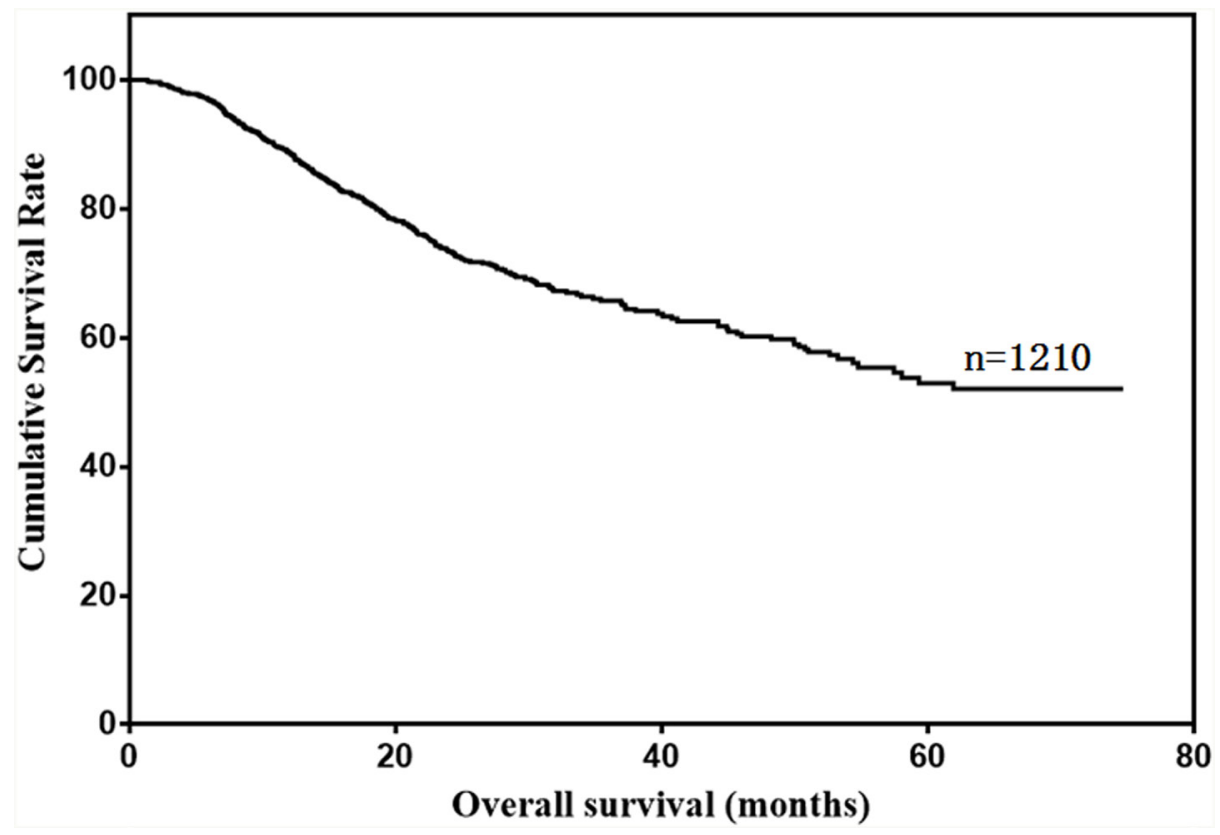

Figure 1: Overall survival of gastric cancer patients. 
We then analyzed the predictive value of FVC in patients with different tumor stages. FVC was not associated with prognosis in stage I and II gastric cancer cases (Figure 4 \& 5). However, low FVC was associated with poor prognosis in patients with stage III gastric cancer (Figure 6). Univariate and multivariate analyses showed that FVC was an independent risk factor for prognosis in stage III gastric cancer patients (Tables $4 \& 5$ ).

Finally, we analyzed relationships between FVC and MVV levels and postoperative complications (Table 6). Low FVC and low MVV were associated with higher rates of postoperative fever $(23.8 \%$ vs. $13.9 \%, \mathrm{P}<0.001$; $17.8 \%$ vs. $13.3 \%, \mathrm{P}=0.049$, respectively). In addition, low FVC was associated with a higher rate of wound infection (1.4\% vs. $0.2 \%, \mathrm{P}=0.029)$.

\section{DISCUSSION}

Pulmonary disease is seldom clinically diagnosed unless a patient presents with overt respiratory symptoms. Thus, preoperative screening for pulmonary disease usually depends on a given patient's previous medical history. Preoperative screening using pulmonary function testing is likely to be more valuable than conventional assessment in terms of evaluating pulmonary abnormalities and predicting postoperative complications [7]. However, while preoperative pulmonary function testing is accepted as an effective tool for predicting operative risk before thoracic surgery [8], it is not yet routinely performed for gastric cancer patients before surgery.

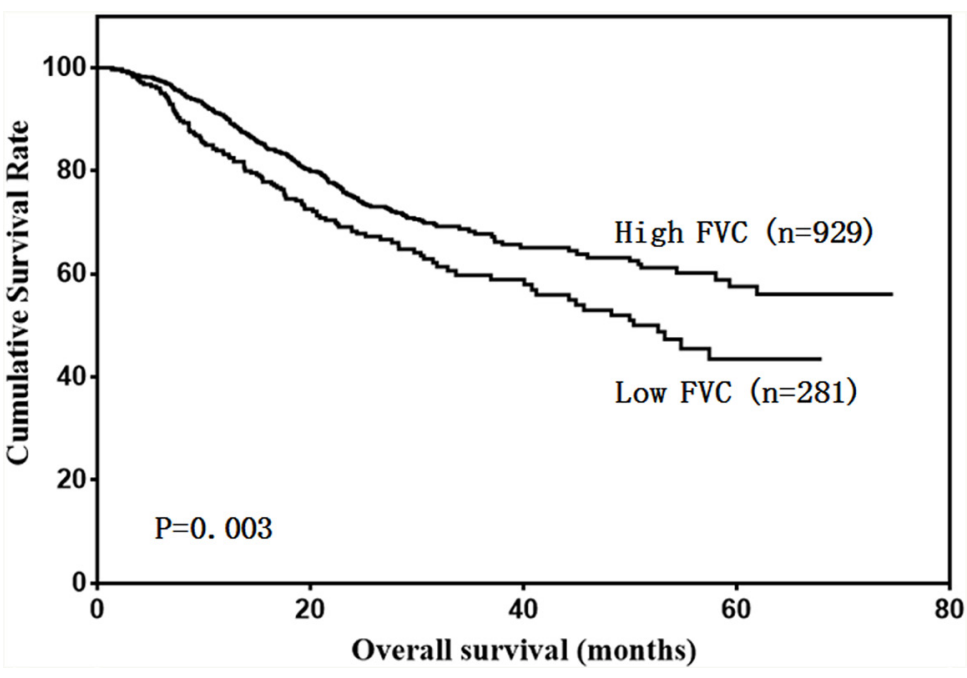

Figure 2: Patient overall survival according to FVC level.

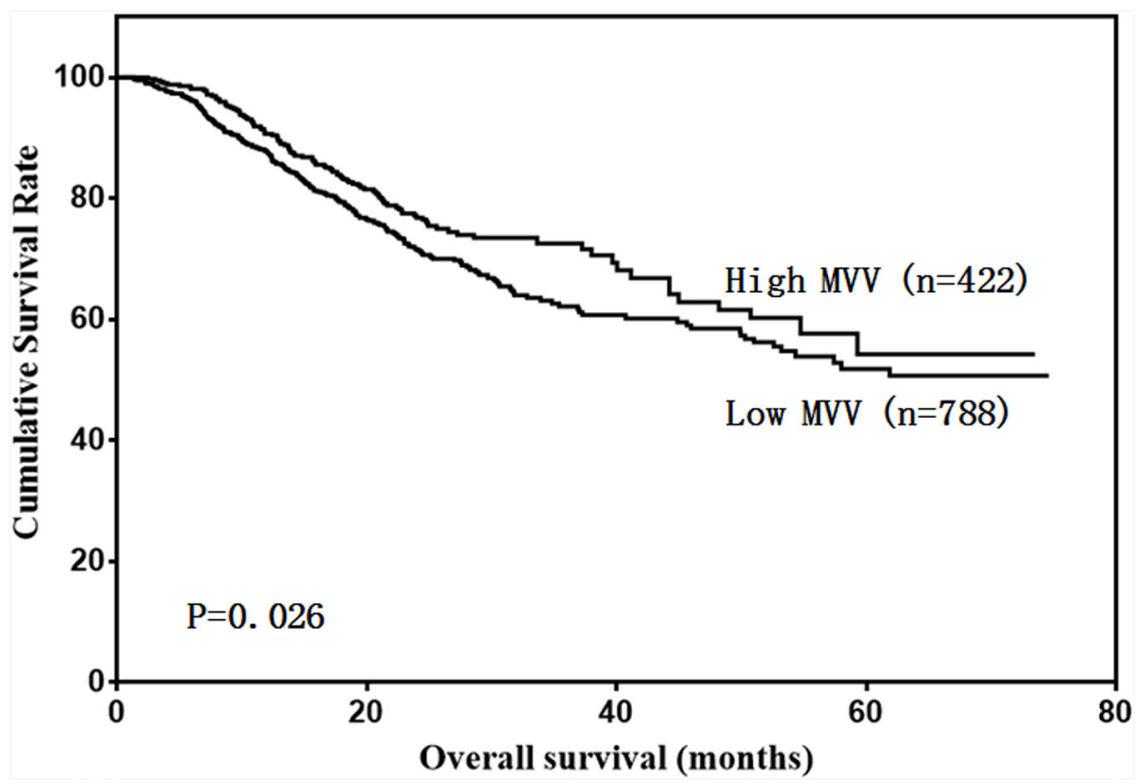

Figure 3: Patient overall survival according to MVV level. 
Table 2: Univariate analysis of risk factors for prognosis of gastric cancer

\begin{tabular}{lccc}
\hline Prognostic factors & $\boldsymbol{\beta}$ & Hazard ratio $\mathbf{( 9 5 \%} \mathbf{C I})$ & P value \\
\hline Gender & -0.119 & $0.888(0.689-1.144)$ & 0.357 \\
Age & 0.383 & $1.466(1.197-1.797)$ & 0.000 \\
BMI & -0.477 & $0.621(0.508-0.759)$ & 0.000 \\
Total protein & -0.249 & $0.780(0.629-0.967)$ & 0.023 \\
Albumin & -0.297 & $0.743(0.592-0.932)$ & 0.010 \\
Tumor location & 0.023 & $1.023(0.923-1.134)$ & 0.667 \\
Tumor size & 0.822 & $2.275(1.857-2.787)$ & 0.000 \\
Borrmann type & 0.212 & $1.236(1.089-1.403)$ & 0.001 \\
Pathological type & 0.535 & $1.707(1.453-2.005)$ & 0.000 \\
Tumor depth & 0.941 & $2.562(2.206-2.977)$ & 0.000 \\
Lymph node metastasis & 0.715 & $2.044(1.851-2.257)$ & 0.000 \\
Tumor stage & 1.379 & $3.970(3.202-4.923)$ & 0.000 \\
FVC & -0.330 & $0.719(0.576-0.897)$ & 0.003 \\
MVV & -0.253 & $0.777(0.622-0.970)$ & 0.026 \\
\hline
\end{tabular}

Table 3: Multivariate analysis of risk factors for prognosis of gastric cancer

\begin{tabular}{lccc}
\hline Prognostic factors & B & Hazard ratio (95\% CI) & P value \\
\hline Age & 0.272 & $1.313(1.064-1.619)$ & 0.011 \\
BMI & -0.328 & $0.720(0.584-0.888)$ & 0.002 \\
Total protein & -0.022 & $0.979(0.742-1.290)$ & 0.878 \\
Albumin & -0.155 & $0.857(0.639-1.148)$ & 0.300 \\
Tumor size & 0.201 & $1.222(0.992-1.507)$ & 0.060 \\
Borrmann type & 0.096 & $1.100(0.976-1.240)$ & 0.118 \\
Pathological type & 0.065 & $1.067(0.887-1.284)$ & 0.494 \\
Tumor depth & 0.594 & $1.811(1.488-2.204)$ & 0.000 \\
Lymph node metastasis & 0.481 & $1.618(1.445-1.811)$ & 0.000 \\
FVC & -0.296 & $0.743(0.590-0.937)$ & 0.012 \\
MVV & -0.097 & $0.908(0.719-1.146)$ & 0.417 \\
\hline
\end{tabular}

Associations between preoperative pulmonary function and postoperative pulmonary complications and patient mortality have been well investigated. However, data describing the impact of pulmonary disease on radical gastrectomy outcomes were controversial. Kim, et al. reported that pulmonary disease was associated with postoperative morbidity in a large, multicenter, laparoscopic gastrectomy study [9]. Jeong, et al. found that preoperative pulmonary function testing effectively predicted the risk of surgical complications and systemic complications in patients undergoing gastrectomy [10]. However, several other studies reported that pulmonary disease did not increase the risk of postoperative complications after gastric cancer surgery [11, 12]. The present study found that low FVC and low MVV were associated with higher incidence of postoperative fever.

The prognostic value of preoperative pulmonary function has mainly been investigated in thoracic surgery $[13,14]$. Guo, et al. reported that FVC was an independent risk factor for the prognosis of non-small cell lung cancer 
patients who underwent curative resection, and $\mathrm{FVC}<80 \%$ predicted poor patient survival [13]. Matsuzaki, et al. associated low forced expiratory volume 1 (FEV1)/FVC ratios with reduced overall and disease-free survival in lung cancer patients undergoing thoracic surgery. The same group found that the carbon monoxide diffusing capacity of the lung and the inspiratory capacity/total lung capacity ratio were associated with patient prognosis [14]. To the best of our knowledge, no previous study has associated preoperative pulmonary function with gastric cancer patient prognosis. Our study associated low FVC and MVV with poor prognosis in gastric cancer patients, and FVC was an independent prognostic predictor.

Cachexia and weight loss in advanced gastric cancer patients were important factors predicting longterm survival. Poor respiratory function may be partly attributed to cancer-induced cachexia. Our study found that although BMI, total protein, and albumin were all associated with gastric cancer patient prognosis, FVC was the only independent risk factor for prognosis.

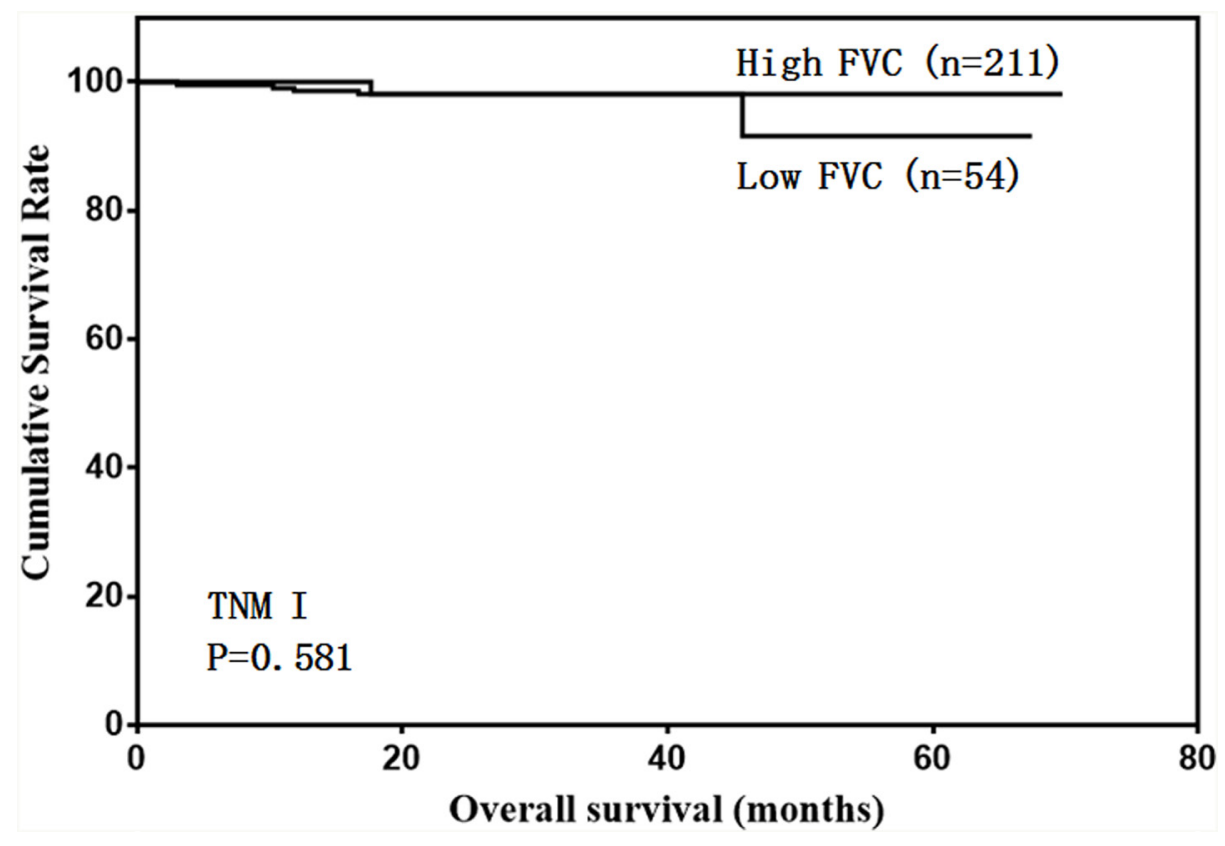

Figure 4: Overall survival of stage I patients according to FVC level.

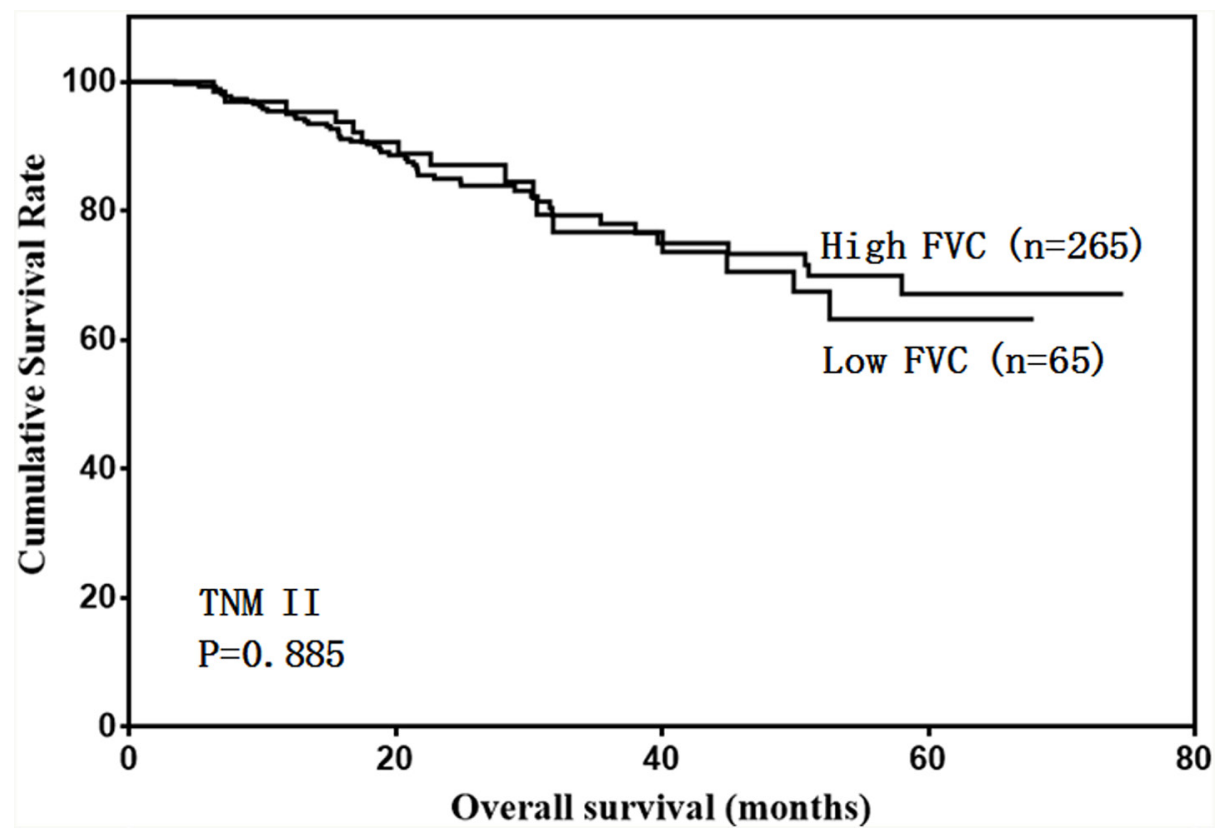

Figure 5: Overall survival of stage II patients according to FVC level. 
Table 4: Univariate analysis of risk factors for prognosis of stage III gastric cancer

\begin{tabular}{|c|c|c|c|}
\hline Prognostic factors & $\boldsymbol{\beta}$ & Hazard ratio $(95 \% \mathrm{CI})$ & P value \\
\hline Gender & -0.031 & $0.969(0.734-1.280)$ & 0.825 \\
\hline Age & 0.234 & $1.264(1.008-1.585)$ & 0.042 \\
\hline BMI & -0.290 & $0.748(0.595-0.941)$ & 0.013 \\
\hline Total protein & -0.075 & $0.927(0.727-1.183)$ & 0.544 \\
\hline Albumin & -0.168 & $0.846(0.653-1.096)$ & 0.205 \\
\hline Tumor location & 0.100 & $1.105(0.989-1.234)$ & 0.077 \\
\hline Tumor size & 0.215 & $1.240(0.989-1.555)$ & 0.062 \\
\hline Borrmann type & 0.122 & $1.130(0.988-1.292)$ & 0.074 \\
\hline Pathological type & 0.176 & $1.192(0.969-1.466)$ & 0.096 \\
\hline Tumor depth & 0.476 & $1.609(1.286-2.015)$ & 0.000 \\
\hline Lymph node metastasis & 0.519 & $1.680(1.372-2.057)$ & 0.000 \\
\hline Lymphatic-vascular invasion & 0.257 & $1.293(0.939-1.780)$ & 0.116 \\
\hline Neural invasion & 0.298 & $1.348(0.845-2.149)$ & 0.210 \\
\hline FVC & -0.294 & $0.745(0.584-0.951)$ & 0.018 \\
\hline MVV & -0.179 & $0.836(0.652-1.073)$ & 0.160 \\
\hline
\end{tabular}

Table 5: Multivariate analysis of risk factors for prognosis of stage III gastric cancer

\begin{tabular}{lccc}
\hline Prognostic factors & $\boldsymbol{\beta}$ & Hazard ratio (95\% CI) & P value \\
\hline Age & 0.228 & $1.256(0.999-1.577)$ & 0.051 \\
BMI & -0.089 & $0.915(0.878-0.953)$ & 0.000 \\
Tumor depth & 0.625 & $1.869(1.489-2.346)$ & 0.000 \\
Lymph node metastasis & 0.614 & $1.848(1.509-2.262)$ & 0.000 \\
FVC & -0.362 & $0.696(0.543-0.893)$ & 0.004 \\
\hline
\end{tabular}

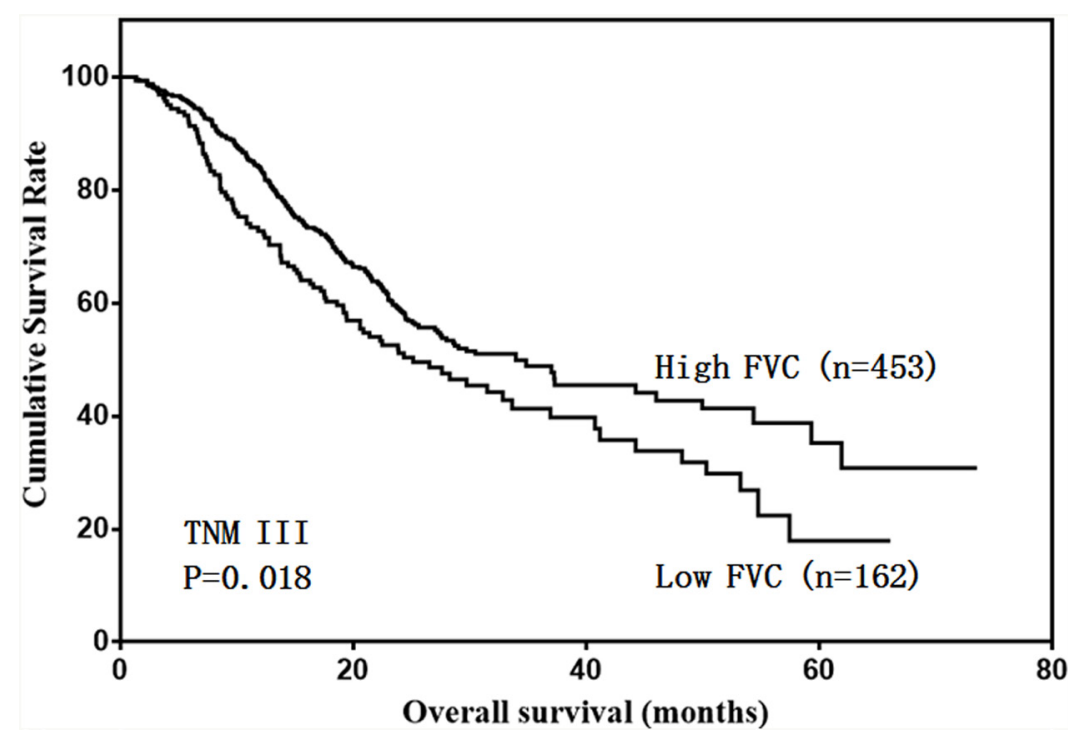

Figure 6: Overall survival of stage III patients according to FVC level. 
Table 6: Comparison of postoperative complications

\begin{tabular}{|c|c|c|c|c|c|c|}
\hline \multirow[b]{2}{*}{ Complications } & \multicolumn{3}{|c|}{ FVC } & \multicolumn{3}{|c|}{ MVV } \\
\hline & $\begin{array}{l}<87.0 \\
n=281\end{array}$ & $\begin{array}{l}\geq 87.0 \\
n=929\end{array}$ & P value & $\begin{array}{l}<83.6 \\
\mathrm{n}=788\end{array}$ & $\begin{array}{l}\geq 83.6 \\
\mathrm{n}=422\end{array}$ & P value \\
\hline Total cases & 110 & 269 & 0.002 & 270 & 109 & 0.003 \\
\hline Fever & 67 & 129 & $<0.001$ & 140 & 56 & 0.049 \\
\hline Pneumonia & 16 & 60 & 0.779 & 56 & 20 & 0.135 \\
\hline Wound infection & 4 & 2 & 0.029 & 6 & 0 & 0.098 \\
\hline Wound disruption & 8 & 8 & 0.017 & 11 & 5 & 1.000 \\
\hline Anastomosis leak & 4 & 12 & 0.773 & 11 & 5 & 1.000 \\
\hline Abdominal bleeding & 1 & 8 & 0.694 & 5 & 4 & 0.727 \\
\hline Chyle leakage & 1 & 12 & 0.320 & 8 & 5 & 0.776 \\
\hline Pleural effusion & 5 & 16 & 1.000 & 14 & 7 & 1.000 \\
\hline Gastric stasis & 0 & 3 & 1.000 & 1 & 2 & 0.280 \\
\hline Ileus & 4 & 18 & 0.799 & 17 & 5 & 0.266 \\
\hline Duodenal stump leak & 0 & 1 & 1.000 & 1 & 0 & 1.000 \\
\hline
\end{tabular}

Multiple groups have investigated the association between FVC and survival in the general population [15-17]. Burnery, et al. reported that FVC, but not airway obstruction, predicts survival in asymptomatic adults without chronic respiratory diagnoses or persistent respiratory symptoms [16]. Low FVC was associated with increased mortality risk [18]. We suggest two possible explanations for these findings, both of which strengthen the case for using pulmonary function testing in gastric cancer patients prior to surgery. First, pulmonary function tests may reflect muscle strength and general energy levels, and physical and psychological disorders may manifest as lower values. Thus, these tests may indicate an individual patient's overall health. Second, poor fetal growth rates and lower birth weights may result in reduced lung function and increased risk of cardiovascular disease $[19,20]$. In these cases, FVC may reflect overall cardiopulmonary function as well as general health.

There were several limitations in our present study. First, it was a retrospective analysis limited to a single center. Multi-center studies are needed to verify the predictive value of FVC. Second, our patient cohort was not large enough, and small sample sizes can result in biased statistical analyses. Third, we did not evaluate the predictive value of FVC after radical gastrectomy. Postoperative pulmonary function may play roles in gastric cancer patient prognosis, and should be explored.

Although preoperative pulmonary function has been associated with postoperative respiratory complications, the prognostic value of preoperative pulmonary function in gastric cancer patients undergoing radical surgery had not yet been investigated. In conclusion, our study demonstrated that low FVC and MVV were associated with poor prognosis and higher rates of postoperative fever in gastric cancer patients, and $\mathrm{FVC}$ was an independent prognostic predictor.

\section{MATERIALS AND METHODS}

This study was performed at the Xijing Hospital of Digestive Diseases affiliated with the Fourth Military Medical University, China. From October 2008 to March 2015, a total of 1210 gastric cancer patients in our department were enrolled in the present study. Inclusion criteria were as follows: 1. without other malignant tumors, 2 . without distant metastasis, 3. without neoadjuvant chemotherapy, 4. with radical D2 gastrectomy, 5 . with preoperative pulmonary function test. This study was approved by the Ethics Committee of Xijing Hospital, and written informed consent was obtained from all patients before surgery.

All patients were treated with proximal, distal or total gastrectomy with D2 lymphadenectomy. The surgical procedure was based on the recommendations of the Japanese Gastric Cancer Treatment Guidelines [21]. Primary tumor depth and degree of lymph node involvement were defined according to the TNM classification. Postoperative chemotherapy was administrated according to the National Comprehensive Cancer Network guidelines.

Pulmonary function test was performed no more than seven days before surgery. FVC and MVV were measured by spirometry. Observed values were expressed as a percent of predicted values. Clinicopathological data, including gender, age, BMI, total protein, albumin, tumor location, tumor size, Borrmann type, type of resection, pathological type, tumor depth, lymph node metastasis and tumor stage, were collected. Postoperative complications, including fever, pneumonia, wound infection, wound 
disruption, anastomosis leakage, abdominal bleeding, chyle leakage, pleural effusion, gastric stasis, ileus and duodenal stump leakage, were also recorded. Patients were followed-up until November 2016, with enhanced chest and abdominal CT and gastroscopy every 3 months.

Data were processed using SPSS 22.0 for Windows (SPSS Inc., Chicago, IL, USA). Optimal FVC and MVV cutoff values for gastric cancer prognosis prediction were calculated using X-tile software [22]. Discrete variables were analyzed using Chi-square test or Fisher's exact test. Significant prognostic risk factors identified by univariate analysis were further assessed by multivariate analysis using the Cox's proportional hazards regression model. Overall survival was analyzed by Kaplan-Meier method. $\mathrm{P} \leq 0.05$ was considered statistically significant.

\section{CONFLICTS OF INTEREST}

The authors declare no conflicts of interest.

\section{GRANT SUPPORT}

This study was supported in part by grants from the National Natural Scientific Foundation of China [NO. 31100643, 31570907, 81300301, 81572306, 81502403, XJZT12Z03].

\section{REFERENCES}

1. Fock KM. Review article: the epidemiology and prevention of gastric cancer. Aliment Pharmacol Ther. 2014; 40:250-60.

2. Marano L, Polom K, Patriti A, Roviello G, Falco G, Stracqualursi A, De Luca R, Petrioli R, Martinotti M, Generali D, Marrelli D, Di Martino N, Roviello F. Surgical management of advanced gastric cancer: An evolving issue. Eur J Surg Oncol. 2016; 42:18-27.

3. Kanat F, Golcuk A, Teke T, Golcuk M. Risk factors for postoperative pulmonary complications in upper abdominal surgery. ANZ J Surg. 2007; 77:135-41.

4. Smetana GW. Preoperative pulmonary evaluation. N Engl J Med. 1999; 340:937-44.

5. Chang HM, Lee SW, Nomura E, Tanigawa N. Laparoscopic versus open gastrectomy for gastric cancer patients with COPD. J Surg Oncol. 2009; 100:456-8.

6. Jeong O, Ryu SY, Park YK. The value of preoperative lung spirometry test for predicting the operative risk in patients undergoing gastric cancer surgery. J Korean Surg Soc. 2013; 84:18-26.

7. Qaseem A, Snow V, Fitterman N, Hornbake ER, Lawrence VA, Smetana GW, Weiss K, Owens DK, Aronson M, Barry P, Casey DE Jr, Cross JT Jr, Fitterman N, et al. Risk assessment for and strategies to reduce perioperative pulmonary complications for patients undergoing noncardiothoracic surgery: a guideline from the American College of Physicians. Ann Intern Med. 2006; 144:575-80.
8. Smetana GW. Preoperative pulmonary evaluation. N Engl J Med. 1999; 340:937-44.

9. Kim W, Song KY, Lee HJ, Han SU, Hyung WJ, Cho GS. The impact of comorbidity on surgical outcomes in laparoscopy-assisted distal gastrectomy: a retrospective analysis of multicenter results. Ann Surg. 2008; 248:793-9.

10. Jeong O, Ryu SY, Park YK. The value of preoperative lung spirometry test for predicting the operative risk in patients undergoing gastric cancer surgery. J Korean Surg Soc. $2013 ; 84: 18-26$.

11. Hwang SH, Park DJ, Jee YS, Kim HH, Lee HJ, Yang HK, Lee KU. Risk factors for operative complications in elderly patients during laparoscopy-assisted gastrectomy. J Am Coll Surg. 2009; 208:186-92.

12. Jeong SH, Ahn HS, Yoo MW, Cho JJ, Lee HJ, Kim HH, Lee KU, Yang HK. Increased morbidity rates in patients with heart disease or chronic liver disease following radical gastric surgery. J Surg Oncol. 2010; 101:200-4.

13. Guo X, Cao H, Xu J, Yu J, Zheng C, Meng L, Du J. Forced vital capacity predicts long-term survival for curativeresected NSCLC. Med Oncol. 2014; 31:146.

14. Matsuzaki A, Hashimoto N, Okachi S, Taniguchi T, Kawaguchi K, Fukui T, Wakai K, Yokoi K, Hasegawa Y. Clinical impact of the lower limit of normal of FEV1/FVC on survival in lung cancer patients undergoing thoracic surgery. Respir Investig. 2016; 54:184-92.

15. Lee HM, Le H, Lee BT, Lopez VA, Wong ND. Forced vital capacity paired with Framingham Risk Score for prediction of all-cause mortality. Eur Respir J. 2010; 36:1002-6.

16. Burney PG, Hooper R. Forced vital capacity, airway obstruction and survival in a general population sample from the USA. Thorax. 2011; 66:49-54.

17. Anderson HR, Vallance P, Bland JM, Nohl F, Ebrahim S. Prospective study of mortality associated with chronic lung disease and smoking in Papua New Guinea. Int J Epidemiol. 1988; 17:56-61.

18. Gray L, Hart CL, Smith GD, Batty GD. What is the predictive value of established risk factors for total and cardiovascular disease mortality when measured before middle age? Pooled analyses of two prospective cohort studies from Scotland. Eur J Cardiovasc Prev Rehabil. 2010; 17:106-12.

19. Barker DJ, Bull AR, Osmond C, Simmonds SJ. Fetal and placental size and risk of hypertension in adult life. BMJ. 1990; 301:259-62.

20. Barker DJ, Godfrey KM, Fall C, Osmond C, Winter PD, Shaheen SO. Relation of birth weight and childhood respiratory infection to adult lung function and death from chronic obstructive airways disease. BMJ. 1991; 303:671-5.

21. Japanese Gastric Cancer Association. Japanese gastric cancer treatment guidelines 2010 (ver. 3). Gastric Cancer. 2011; 14:113-23.

22. Camp RL, Dolled-Filhart M, Rimm DL. Rimm, X-tile: a new bio-informatics tool for biomarker assessment and outcome-based cut-point optimization. Clin Cancer Res. 2004; 10:7252-9. 